Check for updates

Cite this: Nanoscale Adv., 2022, 4, 1718

Received 12th February 2022

Accepted 3rd March 2022

DOI: 10.1039/d2na00097k

rsc.li/nanoscale-advances

\section{Natural wood-derived free-standing films as efficient and stable separators for high- performance lithium ion batteries $\uparrow$}

\author{
Yunlong Yang, ${ }^{a}$ Ning Li, (D) a Tian Lv, ${ }^{a}$ Zilin Chen, ${ }^{a}$ Yanan Liu, ${ }^{a}$ Keyi Dong, ${ }^{a}$ \\ Shaokui $\mathrm{Cao}^{\mathrm{b}}$ and Tao Chen (D)*a
}

\begin{abstract}
A sustainable and low-cost separator is highly required for electrochemical energy storage systems. Herein, a type of modified natural wood film with excellent mechanical properties, ion conductivity and thermal stability is fabricated for high-performance lithium ion batteries. Using the modified natural wood film as a separator, the fabricated symmetric cell exhibits a more stable and lower plating/ stripping voltage for $\mathrm{Li}$ than that of the cell with a commercialized polypropylene (PP) separator. The $\mathrm{LiFePO}_{4} / \mathrm{Li}$ half-cell with the modified wood film separator shows a small polarization voltage and high discharge capacity because of the multi-level nanostructure and abundant functional groups of the modified wood films. The results suggest that the modified wood films are a promising candidate for use as separators in lithium ion batteries. As desired, the $\mathrm{LiFePO}_{4} / \mathrm{Li}$ half-cells with the modified wood film separator deliver much higher discharge capacities and more stable Coulomb efficiency over two hundred charge/discharge cycles than the cell based on the PP separator. The present work systematically investigate the feasibility of abundant and cheap natural wood-derived materials for use as efficient separators instead of synthetic polymers for high-performance lithium ion batteries with long cycle life.
\end{abstract}

\section{Introduction}

The development and utilization of clean energy (such as solar energy, wind energy, water energy, tidal energy) are a powerful means to deal with the energy crisis. ${ }^{1-3}$ To take full advantage of the aforementioned sources of renewable energy and overcome their limitations of intermittence and locality, highly efficient energy storage systems are required. ${ }^{4}$ In the past few decades,

${ }^{a}$ Shanghai Key Lab of Chemical Assessment and Sustainability, School of Chemical Science and Engineering, Tongji University, Shanghai 200092, P. R. China. E-mail: tchen@tongji.edu.cn

${ }^{b}$ School of Materials Science and Engineering, Zhengzhou University, Zhengzhou, 450001, China

$\dagger$ Electronic supplementary information (ESI) available. See DOI: $10.1039 / \mathrm{d} 2 \mathrm{na00097k}$ portable, flexible and wearable electronics (such as notebooks, smartphones, intelligent wrist straps, electronic skin, and so on) have attracted increasing attention and achieved great progress. To meet the power requirements of the above portable electronics, it is urgent to develop high-performance energy storage systems (e.g. metal ion batteries and supercapacitors)..$^{5-7}$ Among various kinds of metal ion batteries, lithium ion batteries (LIBs) have been widely investigated, and are one of the most widely used batteries for portable electronics, due to their high energy density, low self-discharge, good rate performance, and excellent cycle life. ${ }^{\mathbf{8 9}}$ Generally, a lithium ion battery is composed of a positive electrode, negative electrode, electrolyte and separator. Recently, most studies focused on designing new electrode materials and electrolyte to enhance the electrochemical performance of LIBs, and great achievements have been made. ${ }^{10-16}$ As one of the crucial components of LIBs, the separator plays an important role in the properties of lithium ion batteries. Due to their excellent electrochemical stability and ionic accessibility, commercial polyolefins (e.g., polypropylene and polyethylene) are widely used as separators in various kinds of metal ion batteries. ${ }^{17}$ However, the challenges of polyolefins should also be noted. The main problem of polyolefin separators is their limited thermal stability, which will cause serious shrinkage of separators and performance degradation of the resultant batteries under high-temperature working conditions. ${ }^{\mathbf{1 8 , 1 9}}$ In addition, polyolefin materials derived from the cracking of petroleum are expensive and unfriendly to the environment. Therefore, it is greatly meaningful to develop novel separators with high thermal stability, degradability and low cost for high-performance LIBs.

Recently, some studies revealed that functional materials derived from biomass were very promising for use as electrodes and/or separators for electrochemical energy storage. ${ }^{\mathbf{2 0 - 2 4}}$ For instance, $\mathrm{Yu}$ et al. recently reported a chitin nanofiber membrane (CNM) derived from prawn shell for use as a separator in LIBs. ${ }^{22}$ The electrochemical performance of $\mathrm{LiFePO}_{4} / \mathrm{Li}$ half-cells with CNM separators was comparable to that of devices based on a commercial PP separator (Celgard 2325). 
Notably, the CNM separator-based $\mathrm{LiFePO}_{4} / \mathrm{Li}$ batteries exhibited higher stability at $120{ }^{\circ} \mathrm{C}$ than that of devices based on the PP separator. ${ }^{22}$ The ionic conductivity and mechanical performance of the CNMs were further optimized by grafting acrylonitrile on the surface of chitin nanofibers, through which an enhanced electrochemical performance of LIBs could be achieved. ${ }^{23} \mathrm{Mu}$ et al. reported a silk nanofiber membrane with a high tensile stress of 62.75 MPa and Young's modulus of $2.95 \mathrm{GPa}$. Using the silk nanofiber membrane as a separator, supercapacitors with excellent electrochemical performance have been demonstrated. ${ }^{24}$

As one of the most abundant natural polymers, cellulose is widely distributed in plants (e.g., in wood) and animals. ${ }^{25,26}$ Therefore, cellulose nanofibers extracted from wood or other plant material have been widely investigated for use as biomedical materials, ${ }^{27}$ functional membranes, ${ }^{28}$ flexible and biodegradable electronic devices, ${ }^{29}$ and so on. Generally, the extraction of cellulose from plants needs a strong alkali, urea or ionic liquid, which are environmentally unfriendly and expensive. Recently, some researchers attempted to exploit raw wood or simple treatment for use in various fields, such as microfluidics, ${ }^{30}$ water treatment, ${ }^{31}$ energy related devices, ${ }^{32-35}$ and so on. The excellent thermal and electrochemical stability of treated wood materials enables them to be used as highly efficient separators in metal ion batteries, but there has been little research focused on the promising and interesting fields.

Herein, we demonstrated a new type of separator derived from natural wood films for lithium ion batteries with high electrochemical performance and stability. The natural wood was cut into thin films along its growth direction, followed by treatment through a simple hydrothermal approach to remove most of the amorphous hemicelluloses and lignin. The treated natural wood films possess abundant multi-level porous structures and excellent self-supporting ability, which enable them to be used as thinfilm functional membranes for energy storage devices. The best modified natural wood films exhibited high tensile strength $\left(58 \mathrm{MPa}\right.$ ), ionic conductivity of $0.48 \mathrm{mS} \mathrm{cm}^{-1}$ (measured in commercial lithium-ion battery electrolyte) and excellent thermal stability. When using the as-modified wood films as the separators, the developed lithium ion half-cells exhibited comparable
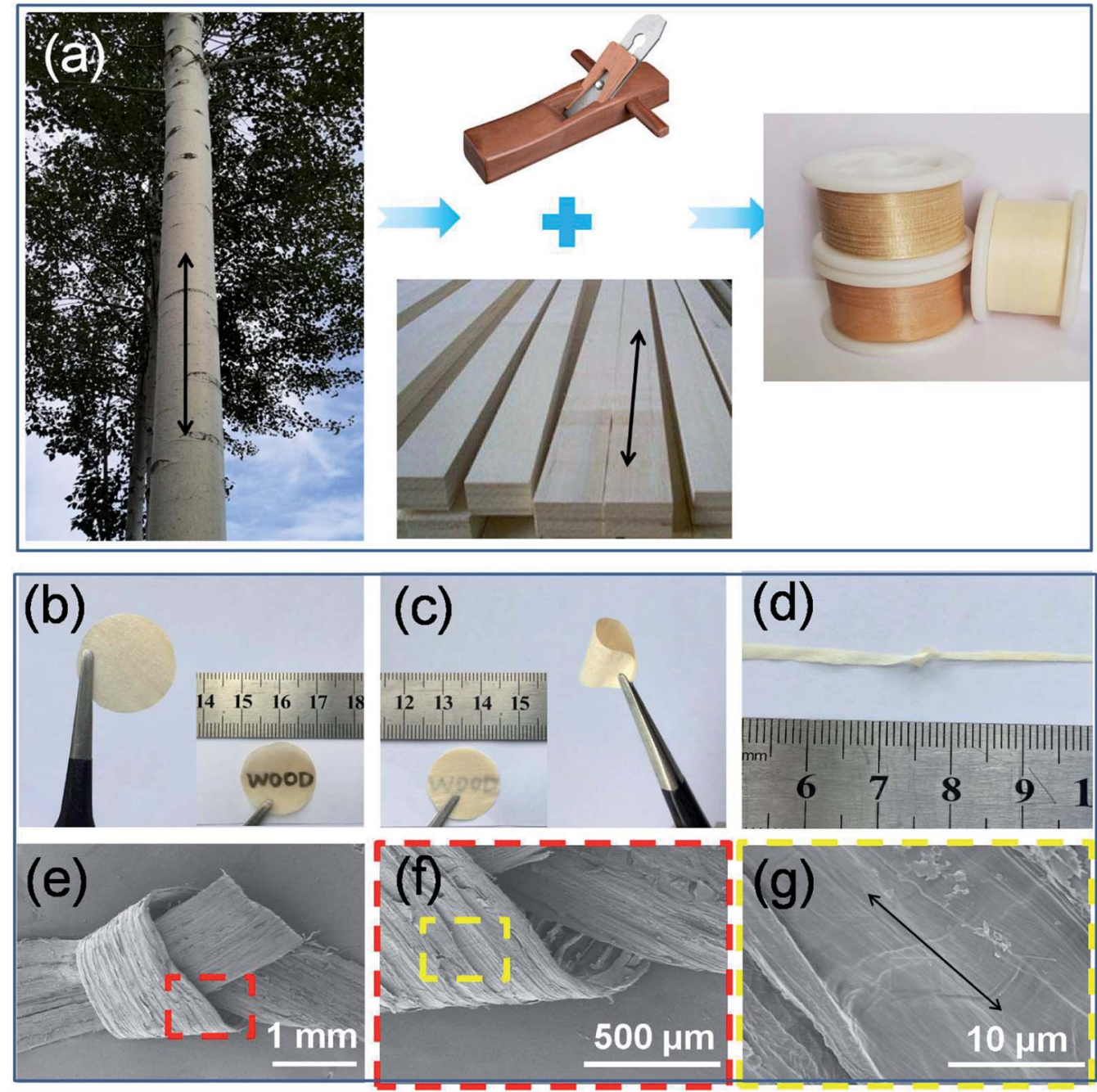

Fig. 1 (a) Schematic and digital photographs of how to fabricate natural wood film from trees. (b-d) The digital photographs of modified poplar wood (wood 3) film under different states. (e-g) SEM images of a tight knot in a long strip of wood film at different magnifications. 
and even better electrochemical performance than that of devices using the commercialized PP separator.

\section{Results and discussion}

As shown in Fig. 1a, natural wood films (thickness of about 80 $\mu \mathrm{m}$ ) with desired sizes were achieved by cutting the wood blocks along their growth direction (black arrow) using a planing machine. Importantly, large-scale production of natural wood films can also be easily realized. In order to remove the lignin and hemicellulose, the raw wood films were treated by a hydrothermal method in a stainless steel reactor using an aqueous solution mixture of $\mathrm{NaOH}$ and $\mathrm{Na}_{2} \mathrm{SO}_{3}$, followed by repeatedly washing with deionized water (Fig. S1†). The astreated natural wood films were freeze-dried, through which the pores formed during removal of lignin and hemicellulose can be well retained. The as-prepared natural wood films can be easily cut into desired shapes (e.g., circles with a diameter of $18 \mathrm{~mm}$ for button batteries, Fig. 1b). The modified wood films can be bent (Fig. 1c and S2 $\dagger$ ) and even tied into a knot (Fig. 1d) without structural damage, and they can fully restore their original shapes after the twisting force is released (Fig. S3 $\dagger$ ), suggesting excellent mechanical flexibility. From the scanning electron microscope (SEM) images shown in Fig. 1e-g, it can be seen that there were no obvious changes or breakage at different areas of the knot, which indicated the highly stable structure of the modified wood film under deformation conditions. In order to investigate the relationship between the structure and performance of the modified wood films, we chose three types of natural wood (basswood, pine wood and poplar wood named wood 1 , wood 2 and wood 3 , respectively) with different structures and densities for further studies.

The structures and constituents of the natural wood films before and after chemical modification (Fig. 2a) were (a)

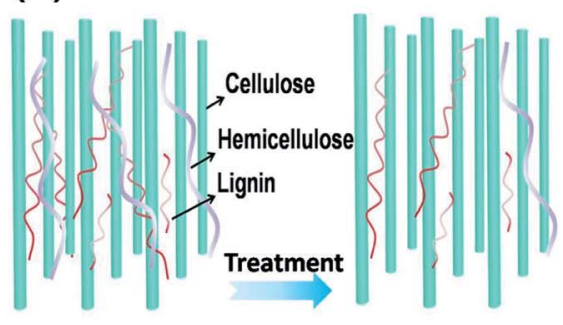

(b)

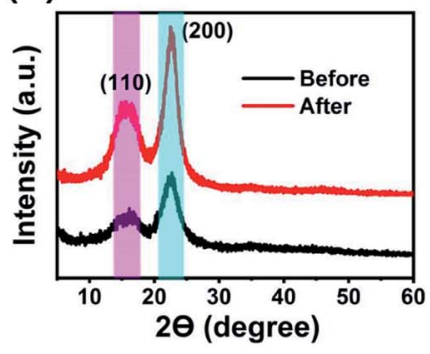

(c)

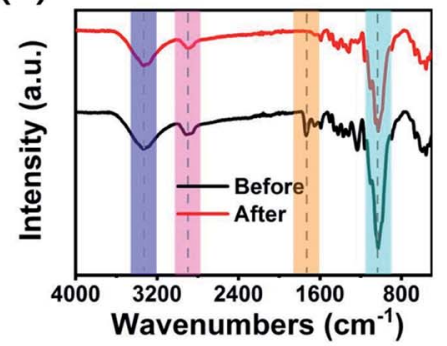

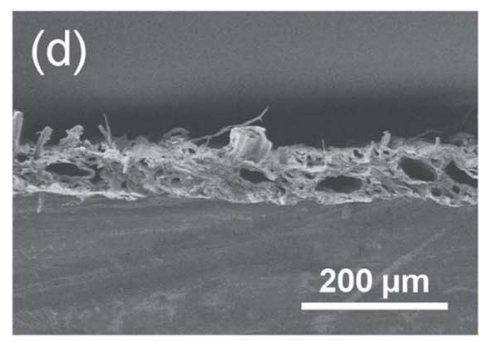
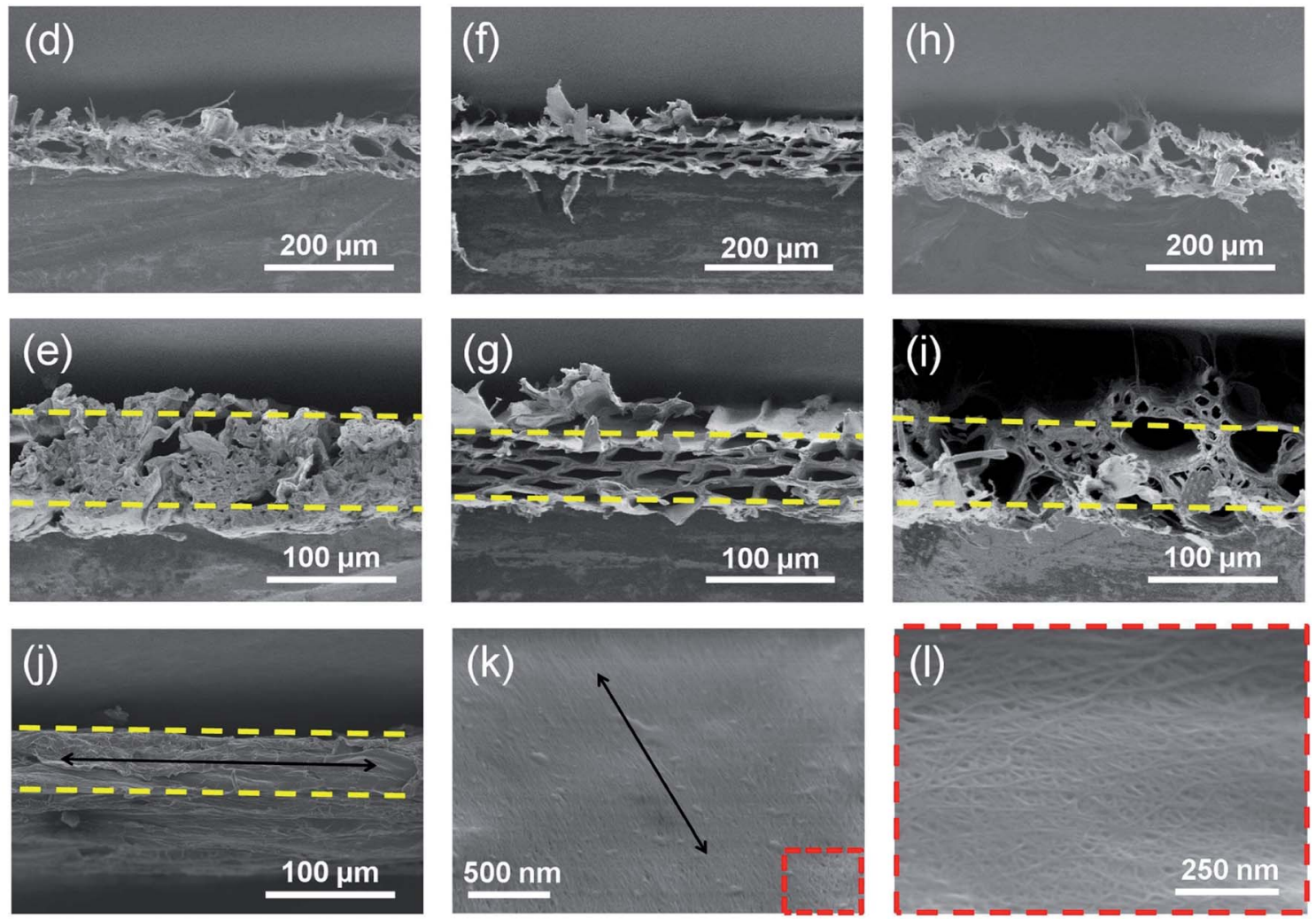

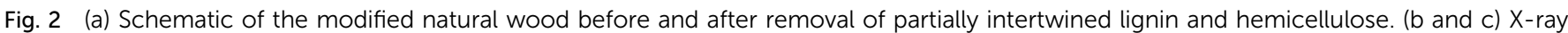

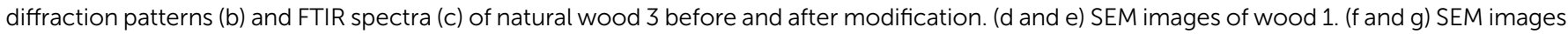
of wood 2. (h and i) SEM images of wood 3. ( $j-l)$ Side-view and top-view SEM images of the modified wood 3 film. 
investigated by X-ray diffraction (XRD) and Fourier transform infrared (FTIR) spectroscopy. As shown in Fig. 2b, two main peaks at about $16.20^{\circ}$ and $18.30^{\circ}$ were observed, which can be assigned to the (110) and (200) crystallographic planes of cellulose,$^{36,37}$ respectively. After removing the disordered components of amorphous lignin and hemicellulose, the peak intensity of the chemically modified wood film was obviously enhanced, because the main component of cellulose possessed high crystallinity and an oriented structure. The same phenomenon was also observed in the XRD data of wood 1 and wood 2 (Fig. S4 $\dagger$ ). The FTIR spectra (Fig. 2c and S5 $\dagger$ ) also confirmed that lignin and hemicellulose were partially removed after chemical modification. ${ }^{38-40}$ Especially for wood 3, the characteristic peaks at $3324 \mathrm{~cm}^{-1}$ and $2890 \mathrm{~cm}^{-1}$ represented the stretching vibration of $-\mathrm{OH}$ groups and saturated $\mathrm{C}-\mathrm{H}$. The peaks at 1035, 1079, and $708 \mathrm{~cm}^{-1}$ can be assigned to $-\mathrm{SO}_{3}$ vibrational groups. The characteristic bands at $1503 \mathrm{~cm}^{-1}$ suggested the presence of aromatic rings of the phenyl propane skeleton in all the modified natural wood films (Fig. S5†).

The color of all the wood films obviously changed after treatment (Fig. S6†). Compared with the natural wood films without modification (Fig. S7†), the film modified from wood 2 showed more serious shrinkage than films from wood 1 and 3 . This can be ascribed to the weak interaction among lignin, hemicellulose and cellulose in wood 2. From SEM images (Fig. 2d-j), the wood films showed a porous structure and thickness ranging from 60 to $80 \mu \mathrm{m}$. The film of modified wood 1 showed a relatively compact structure (Fig. 2d and e) with a few big holes $(40-70 \mu \mathrm{m})$ and some small holes $(3-10 \mu \mathrm{m})$. The film of modified wood 2 exhibited uniform diamond-shaped holes with diameters ranging from 20 to $40 \mu \mathrm{m}$ (Fig. $2 \mathrm{f}$ and $\mathrm{g})$. Interestingly, the modified wood 3 possessed a multi-level porous structure with big holes ranging from 30 to $40 \mu \mathrm{m}$ and numerous small holes ranging from 4 to $8 \mu \mathrm{m}$ (Fig. $2 \mathrm{~h}$, i and $\mathrm{S} 8 \dagger$ ). As a result, the unique multi-level porous structure endowed the film of wood 3 with the highest porosity (Fig. S9 $\dagger$ ), which was in good accordance with the morphologies of wood films. As Fig. 2j showed, the modified wood film possessed a uniform thickness of about $80 \mu \mathrm{m}$, and most of the cellulose fibers were well aligned along the growth direction of the wood (Fig. 2k and l).

The thermal stability, mechanical properties and lithium ion transfer ability of the modified natural wood films were also characterized to validate their feasibility for use as separators in high-performance lithium batteries. As Fig. 3a shows, all the chemically modified wood films can well maintain their shapes without obvious shrinkage occurring within the temperature range from 80 to $140{ }^{\circ} \mathrm{C}$. In comparison, the widely used PP separator in lithium ion batteries shrunk seriously (Fig. 3a) when the temperature was higher than $80{ }^{\circ} \mathrm{C}$. The higher thermal stability of the modified wood films than the commercial PP separator can be ascribed to their higher thickness and 3D network structure, though the decomposition temperature of PP was higher than those of the modified wood films (Fig. S10 $\dagger$ ). Mechanical measurements indicated that the film derived from wood 3 showed a tensile strength of $58 \mathrm{MPa}$ (Fig. 3b), which was higher than those of most previously reported biomass membranes (Table S1 $\dagger$ ). Both films derived (a)

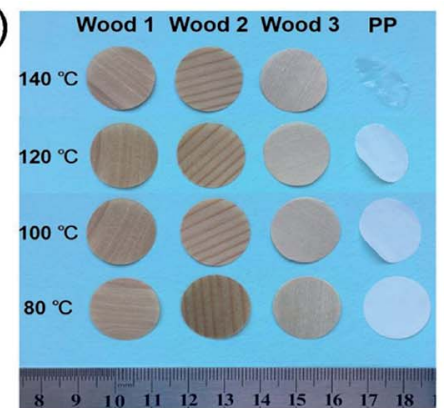

(d)

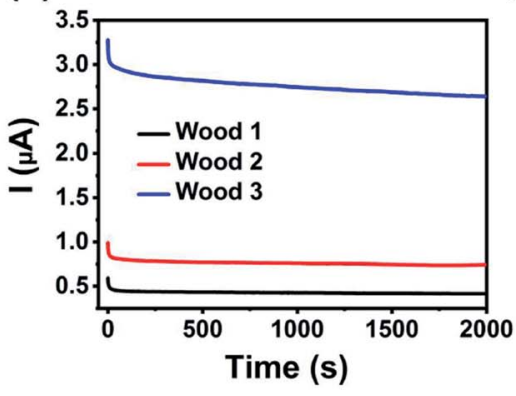

(b)

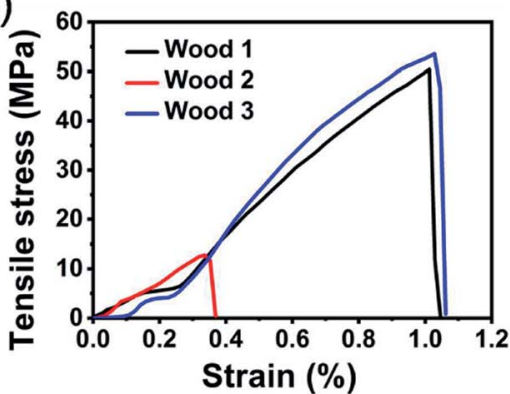

(e)

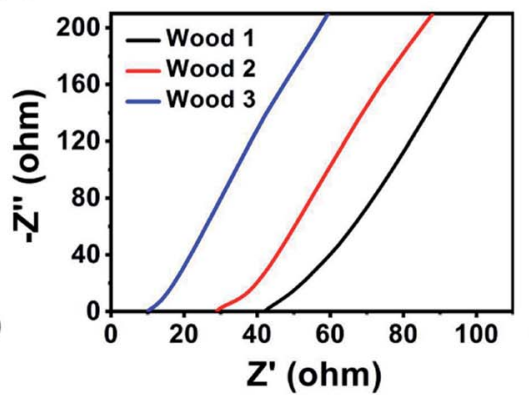

(c)

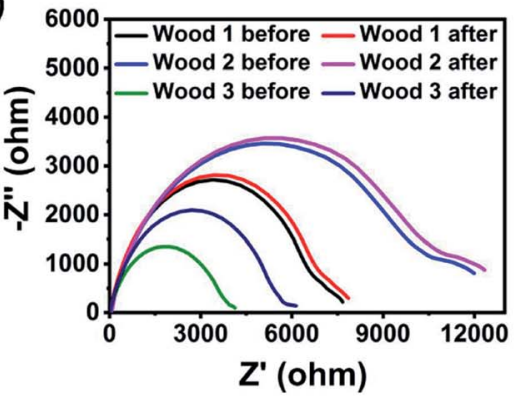

(f)

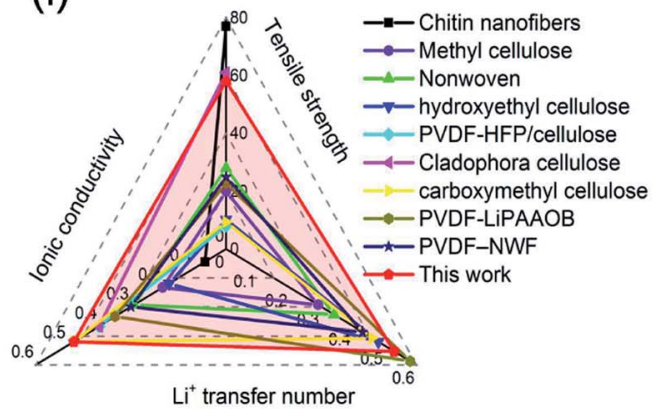

Fig. 3 (a) Thermal stability of the PP separator and three different modified natural wood films at different temperatures. (b) Tensile stress-strain curves of different modified natural wood films. (c) Nyquist plots of symmetrical Li/separator/Li cells with different wood-derived separators before and after polarization. (d) The current-time curves of symmetrical Li/separator/Li cells with different wood-derived separators obtained by direct-current polarization. (e) Nyquist plots of symmetric stainless steel/separator/stainless steel cells based on different wood-derived separators. (f) Comparison of performance of the wood 3-derived film with other separators used for batteries. 
from wood 1 and 3 exhibited higher tensile strengths and strains than that from wood 2 because of their hierarchical porous structure and strong interaction between cellulose fibres.

The lithium ion transference number of the separator also plays a crucial role in the electrochemical performance of rechargeable lithium ion batteries. ${ }^{41-43}$ All the Nyquist plots (Fig. 3c) display a semicircle and an inclined spur in the highfrequency region and low-frequency region, respectively. According to a previously reported method, ${ }^{43}$ the lithium ion transference number of the films derived from wood $1(0.32)$, wood $2(0.42)$ and wood $3(0.53)$ can be calculated from Nyquist plots (Fig. 3c) and chronoamperometry curves (Fig. 3d). All the values were higher than that of the commercial separator $(0.27){ }^{42}$ The lithium ion transference number of the chemically modified wood films could be ascribed to the formed hydrogen bonds between the hydroxyl groups in cellulose nanofibrils and fluorine atoms in $\mathrm{PF}_{6}{ }^{-}$, which will restrict the movement of anions and promote the migration of lithium ions. ${ }^{43}$ The ionic conductivities of the developed chemically modified wood films were investigated in symmetric stainless steel/wood film separator/stainless steel cells using the commercial electrolyte of $1 \mathrm{M} \mathrm{LiPF}_{6}$ in ethylene carbonate/diethyl carbonate (volume ratio of $1: 1$ ). From Fig. 3e, it can be calculated that the ionic conductivities of wood 1 , wood 2 and wood 3 were $0.12,0.19$ and $0.48 \mathrm{mS} \mathrm{cm}^{-1}$, respectively. Because of its unique hierarchical porous structure, the film derived from wood 3 exhibited an excellent combination of mechanical strength, ionic conductivity and lithium ion transference number, which are better than those of most reported biomass-derived separators for lithium ion batteries (Fig. $3 \mathrm{f}$ and Tables S1 and S2†). All the results demonstrated aforementioned revealed that the chemically modified wood films represent promising candidates for use as novel separators in lithium ion batteries.

With the modified natural wood films as the separators, halfcells were fabricated and investigated using lithium iron phosphate and a lithium plate as the positive and negative electrodes, respectively. The half-cell with wood 3 as the separator delivered a discharge capacity of $141.2 \mathrm{~mA} \mathrm{~h} \mathrm{~g}^{-1}$, which is higher than those of cells based on wood $2\left(139 \mathrm{~mA} \mathrm{~h} \mathrm{~g}^{-1}\right)$ and wood $1\left(128 \mathrm{~mA} \mathrm{~h} \mathrm{~g}^{-1}\right)$ as the separators. Moreover, the half-cell based on wood 3 as the separator exhibited a lower voltage difference between the charging and discharging plateaus (Fig. 4a) than those of cells using the other two types of natural wood derived separators, which indicated that the separator derived from wood 3 was more suitable for the diffusion of ions because of its superior combined properties. In comparison, the half-cell using the natural wood film without modification as the separator exhibited a large polarization voltage and low discharge capacity (Fig. S11†), while the half-cell using the modified wood film dried in an ordinary oven also showed low capacity and serious polarization, indicating large resistance to ion transmission (Fig. S12 $\dagger$ ). The electrochemical impedance spectroscopy results (Fig. 4b and c) showed that the half-cells (a)

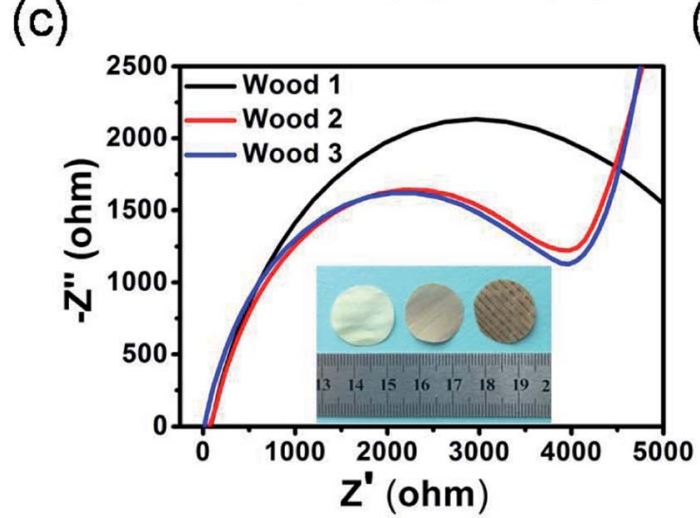

(b)

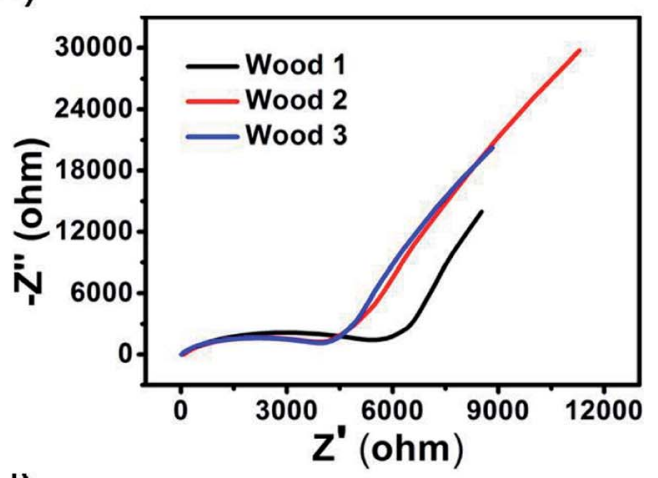

(d)

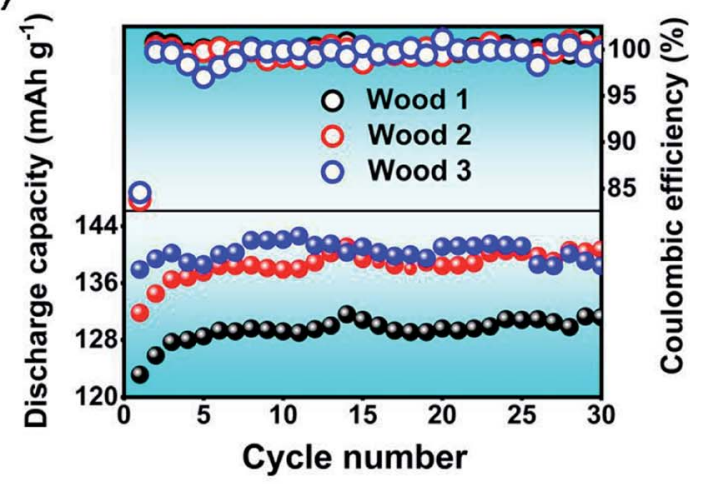

Fig. 4 Charge/discharge voltage profiles (a) and Nyquist plots (b and c) of the LiFePO $4 /$ Li half-cells with different wood-derived separators. (d) Cycling performance of the $\mathrm{LiFePO}_{4} / \mathrm{Li}$ half-cells based on different wood-derived separators $(0.5 \mathrm{C})$. 
using the separators derived from wood 2 and 3 presented much lower transfer resistance to lithium ions than the half-cell using wood 1. As Fig. 4d shows, the half-cell using the separator derived from wood 3 also delivered a highly stable discharge capacity and coulombic efficiency over 30 cycles. Meanwhile, the cells with the other two separators also showed a relatively stable cycle performance, but with relatively low capacities. Therefore, we further investigated the potential application of the chemically modified wood 3 film as a separator for building lithium ion batteries with high performance, compared with the most commonly used PP separator.

From the linear sweep voltammetry (LSV) curves shown in Fig. 5a, it can be seen that the separator derived from wood 3 exhibited a highly stable electrochemical window up to $5.0 \mathrm{~V}$ versus $\mathrm{Li}^{+} / \mathrm{Li}$ with no obvious decomposition, which was comparable with that of the PP separator. With stainless steel, metallic lithium and the modified film of wood 3 (or PP) as the working electrode, counter electrode and the separator, respectively, the assembled asymmetric battery showed similar shapes of curves in the range from 0.5 to $5.0 \mathrm{~V}$ (Fig. S13 $\dagger$ ). For the symmetric $\mathrm{Li} / \mathrm{Li}$ cell using the chemically modified wood 3 separator, the homogeneous and smooth morphology of the $\mathrm{Li}$ electrode can be clearly observed (Fig. 5b) after stripping/ plating for 500 hours. In comparison, an undesirable rough surface and visible "dead $\mathrm{Li}$ " on the Li electrode were formed when using the PP separator (Fig. 5c). The results indicated that the modified wood films could be used as promising separators to stabilize the SEI and enable dendrite-free $\mathrm{Li}$ anodes for lithium ion batteries. The voltage profiles (Fig. 5d, e and S14 $\dagger$ ) showed that the symmetric cell using the separator derived from wood 3 exhibited a very stable overpotential as low as $18 \mathrm{mV}$ during the entire Li plating/stripping process at both low $\left(1 \mathrm{~mA} \mathrm{~cm}{ }^{-2}\right)$ and high $\left(5 \mathrm{~mA} \mathrm{~cm} \mathrm{~cm}^{-2}\right)$ current densities. In contrast, the overpotential of the cell with the PP separator dramatically increased after tens of hours at both low and high current densities (Fig. 5d, e and S14 $\dagger$ ). The stable voltage curve during the plating/stripping process of $\mathrm{Li}$ in symmetric cells indicated that a uniform solid electrolyte interphase could be formed on the $\mathrm{Li}$ anode, resulting in a very stable electrochemical performance. These results can be attributed to the abundant functional groups in the modified wood films (Fig. 5g) having high affinity for Li ions, ${ }^{44}$ which resulted in (a)

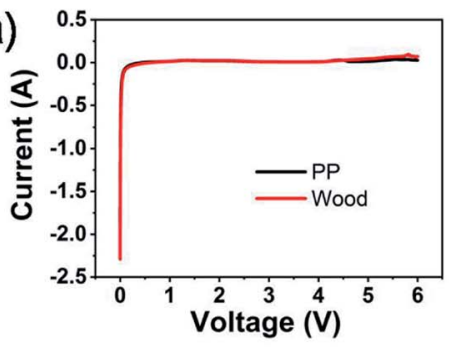

(d)

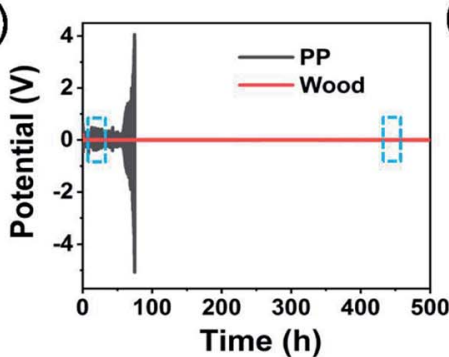

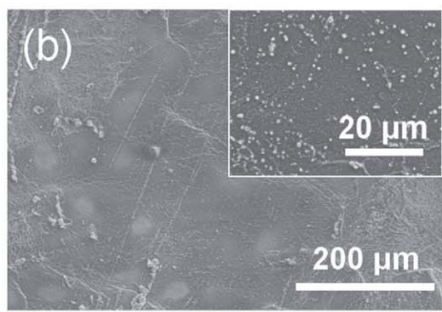

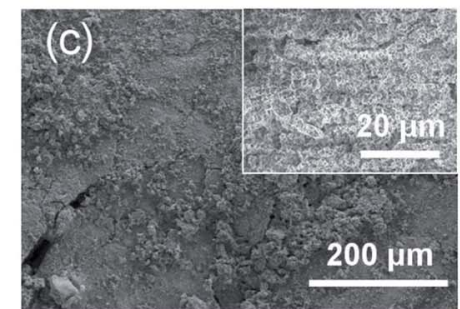

(e)
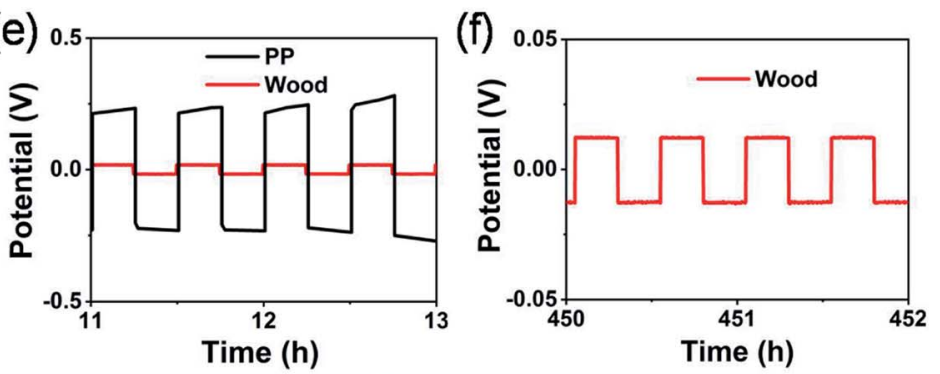
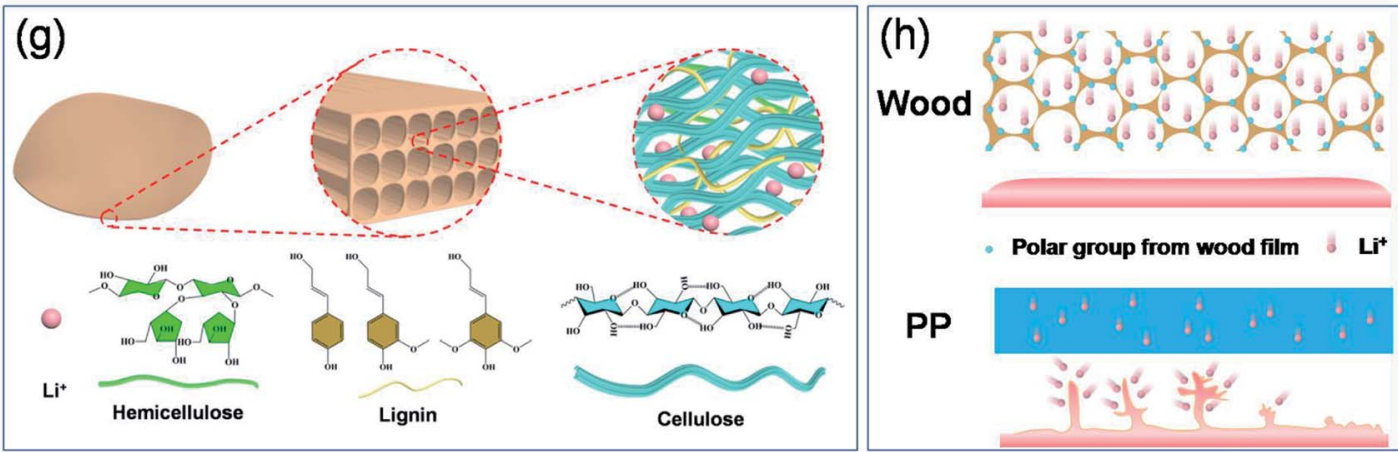

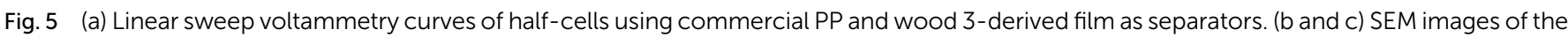

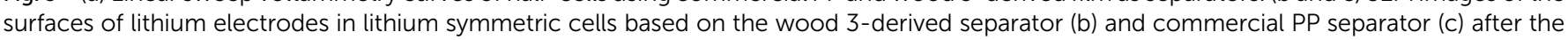

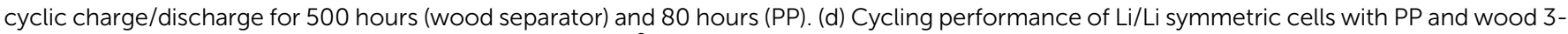

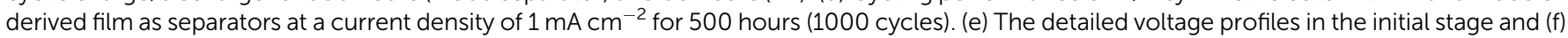

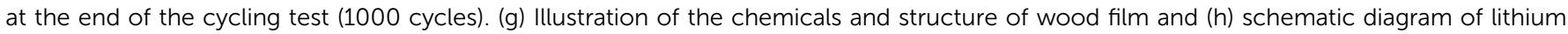
dendrite growth for wood and PP separators. 
uniform deposition of lithium and suppressed growth of $\mathrm{Li}$ dendrites on the electrode (Fig. 5h). Moreover, the multi-level porous structure of the natural wood derived separators also provided efficient channels for diffusion of $\mathrm{Li}$ ions and enough space to allow the volume changes of electrode materials, which is very helpful to achieve high-performance lithium ion batteries.

The electrochemical performance of $\mathrm{LiFePO}_{4} / \mathrm{Li}$ half-cells (Fig. 6a) based on the separators derived from wood 3 and PP has been systematically investigated. As Fig. $6 \mathrm{~b}$ showed, the cell based on the separator derived from wood 3 delivered a slightly higher discharge capacity than that of the cell with the PP separator, and their potential plateaus in the charge-discharge profiles were almost the same. The $\mathrm{CV}$ curves of the half-cell based on the separator derived from wood 3 (Fig. S15 $\dagger$ ) showed oxidation and reduction peaks at around 3.62 and $3.22 \mathrm{~V}\left(v s . \mathrm{Li}^{+} / \mathrm{Li}\right)$, and the peak separation was $0.4 \mathrm{~V}$, similar to those of cells using other biomass membranes as separators (Table S3†). Fig. 6c and d show that the cell based on the separator derived from wood 3 exhibited comparable discharge capacity with that of the cell with the PP separator. The polarization voltage (Fig. 6f) of the cell based on the separator derived from wood 3 was very stable even after 200 cycles, which was better than those of most cells based on other biomass and composite membranes reported previously (Table S3†). Fig. $6 \mathrm{~g}$ indicates that the cell using the separator derived from wood 3 exhibited comparable stability of capacity and Coulomb efficiency with that of the PP separator-based cell, indicating (a)

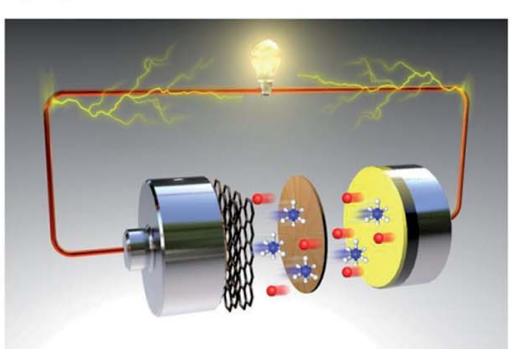

(d)

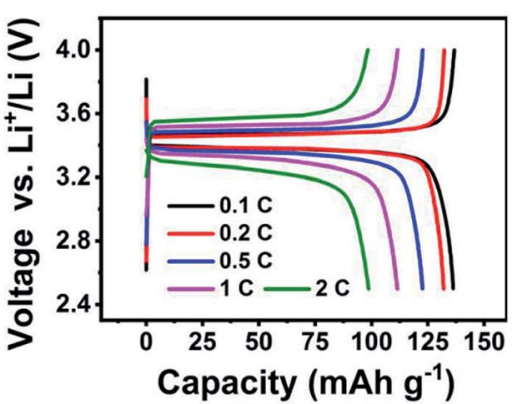

(g)

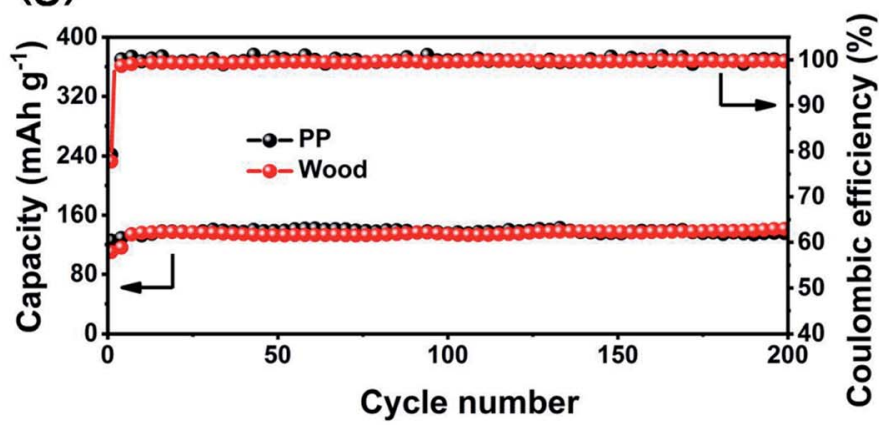

(e) (c)
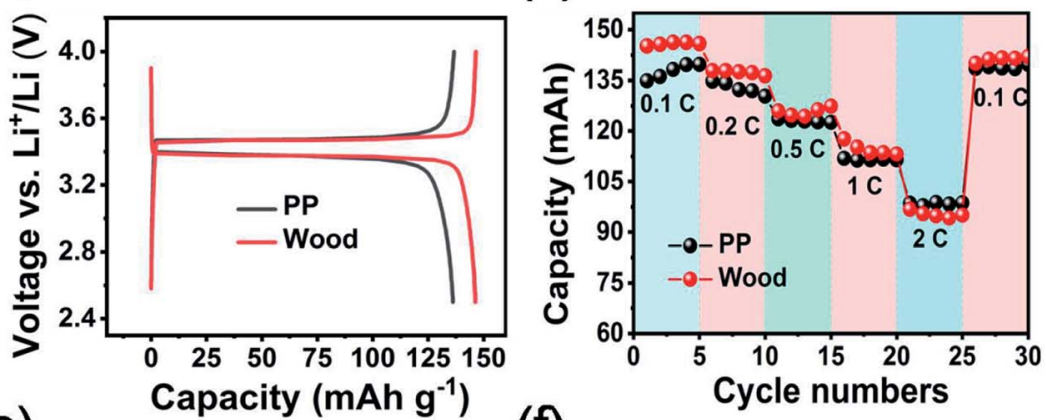

(f)
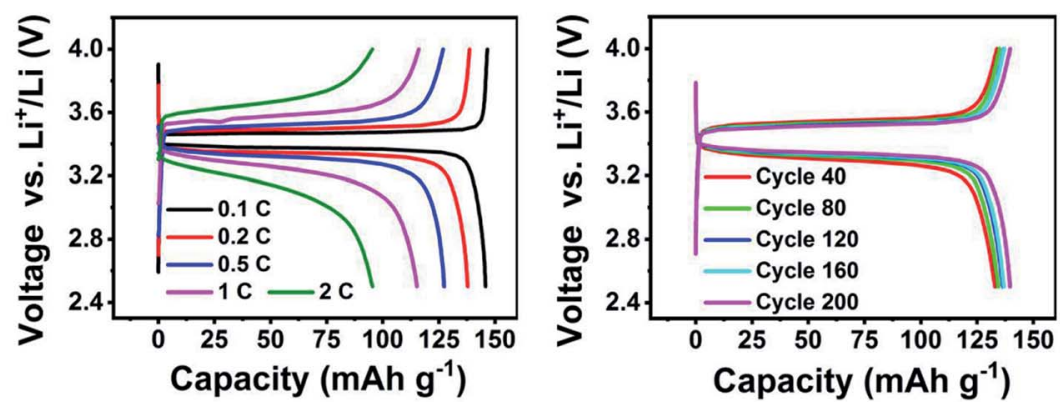

(h)

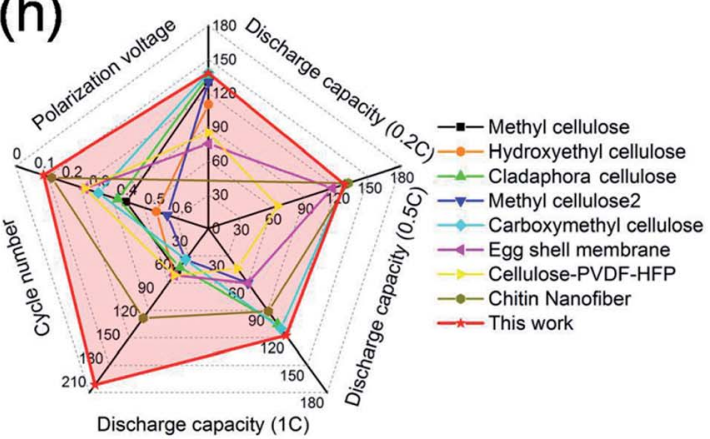

Fig. 6 (a) Schematic of a lithium ion battery using a natural wood-derived separator. (b) Charge/discharge voltage profiles of the LiFePO $4 /$ Li halfcells using the PP separator and wood 3-derived separator film at $0.1 \mathrm{C}\left(1 \mathrm{C}=170 \mathrm{~mA} \mathrm{~g}^{-1}\right)$. (c) Rate performance of LFP half-cells based on PP and wood 3-derived film as the separators at different current densities in the voltage range from 2.5 to $4.0 \mathrm{~V}$. (d and e) Voltage profiles of the cells using PP (d) and wood 3-derived separators (e) at different charge/discharge rates, respectively. (f) Voltage profiles of the cells using the wood 3derived film separator for different numbers of cycles. (g) The cycling performance of the cells using the commercial PP and wood 3-derived film separators at $0.2 \mathrm{C}$ conducted at room temperature. (h) Comparison of the electrochemical performance of our lithium ion battery with that of other reported devices using biomass separators. 
excellent cycling performance. A soft-packing lithium ion battery with the wood derived separator that can continuously power a light emitting diode with a working voltage of $2.0 \mathrm{~V}$ under different bending states (Fig. S16†) has also been achieved. The lithium ion battery based on the newly developed wood-derived separator delivered comparable electrochemical performance and even much better rate capability (Fig. 6h and Table S3†) than that of devices with cellulose or biomass separators reported previously.

\section{Conclusion}

In summary, we demonstrated a novel natural wood-derived separator for high-performance lithium ion batteries. The natural wood-derived separators well maintaining the intrinsic porous structure of the protogenic wood were fabricated by directly solution traiting planing rare wood films. The obtained modified natural wood films not only exhibited excellent mechanical properties and thermal stability, but also possessed high ionic conductivity and lithium ion transference number. Using the modified wood films as separators, a uniform SEI could be formed on the surface of the Li electrode without formation of dendrites, which endowed the developed lithium ion battery with long cycling stability, high specific capacity and good rate performance, comparable with those of devices based on a commercial PP separator. Benefiting from the low cost and sustainability of the biomass materials, the natural woodderived films have great potential to be used as efficient separators in the field of energy storage, beyond lithium ion batteries.

\section{Conflicts of interest}

The authors declare no conflict of interest.

\section{Acknowledgements}

This work is supported by the National Natural Science Foundation of China (21774094, 51973159 and 22179097), Science \& Technology Commission of Shanghai Municipality (14DZ2261100), and the Program for Professor of Special Appointment (Eastern Scholar) at Shanghai Institutions of Higher Learning.

\section{References}

1 H. Sun, Y. Zhang, J. Zhang, X. Sun and H. Peng, Nat. Rev. Mater., 2017, 2, 17023.

2 T. Li, J. Sun, S. Gao, B. Xiao, J. Cheng, Y. Zhou, X. Sun, F. Jiang, Z. Yan and S. Xiong, Adv. Energy Mater., 2021, 11, 2003699.

3 T. Chen, L. Qiu, Z. Yang and H. Peng, Chem. Soc. Rev., 2013, 42, 5031-5041.

4 Z. Li, X. Wang, Z. Wang, L. Wang, Y. Guo, C. Zhou, X. Li, K. Du and Y. Luo, J. Colloid Interface Sci., 2022, 608, 70-78.

5 T. Lv, Y. Yao, N. Li and T. Chen, Nano Today, 2016, 11, 644660.
6 W. Wu, X. Wang, Y. Deng, C. Zhou, Z. Wang, M. Zhang, X. Li, Y. Wu, Y. Luo and D. Chen, Nanoscale, 2020, 12, 17738.

7 S. Gao, P. Ju, Z. Liu, L. Zhai, W. Liu, X. Zhang, Y. Zhou, C. Dong, F. Jiang and J. Sun, J. Energy Chem., 2022, 69, 356-362.

8 M. Lukatskaya, B. Dunn and Y. Gogotsi, Nat. Commun., 2016, 7, 12647.

9 B. Dunn, H. Kamath and J. Tarascon, Science, 2011, 334, 928935.

10 W. Ping, C. Wang, R. Wang, Q. Dong, Z. Lin, A. Brozena, J. Jia, J. Luo and L. Hu, Sci. Adv., 2020, 6, eabc8641.

11 J. Wang, A. E. Lakraychi, X. Liu, L. Sieuw, C. Morari, P. Poizot and A. Vald, Nat. Mater., 2020, 20, 1-9.

12 W. Zhang, D. H. Seo, T. Chen, L. Wu, M. Topsakal, Y. Zhu, D. Lu, G. Ceder and F. Wang, Science, 2020, 367, 1030-1034. 13 Y. Bi, J. Tao, Y. Wu, L. Li, Y. Xu, E. Hu, B. Wu, J. Hu, C. Wang, J. Zhang, Y. Qi and J. Xiao, Science, 2020, 370, 1313-1317.

14 C. Zhao, Q. Wang, Z. Yao, J. Wang, B. Sánchez-Lengeling, F. Ding, X. Qi, Y. Lu, X. Bai, B. Li, H. Li, A. Aspuru-Guzik, X. Huang, C. Delma, M. Wagemaker, L. Chen and Y. Hu, Science, 2020, 370, 708-711.

15 H. Liu, Z. Zhu, Q. Yan, S. Yu, X. He, Y. Chen, R. Zhang, L. Ma, T. Liu, M. Li, R. Lin, Y. Chen, Y. Li, X. Xing, Y. Choi, L. Gao, H. Cho, K. An, J. Feng, R. Kostecki, K. Amine, T. Wu, J. Lu, H. Xin, S. On and P. Liu, Nature, 2020, 585, 63-67.

16 H. Jin, S. Xin, C. Chuang, W. Li, H. Wang, J. Zhu, H. Xie, T. Zhang, Y. Wan, Z. Qi, W. Yan, Y. Lu, T. Chan, X. Wu, J. Goodenough and H. Ji, Science, 2020, 370, 192-197.

17 M. Lagadec, R. Zahn and V. Wood, Nat. Energy, 2019, 4, 1625.

18 J. Kim, M. Gu, D. Lee, J. Kim, Y. Oh, S. H. Min, B. Kim and S. Lee, Nano Lett., 2016, 16, 5533-5541.

19 Q. Song, A. Li, L. Shi, C. Qian, Y. Fu, H. Zhang, Z. Li, P. Wang, Z. Li, H. Zhai, X. Wang, M. Dontigny, K. Myers, X. Chuan and Y. Yang, Energy Storage Mater., 2019, 22, 48-56.

20 B. Yu, K. Park, J. Jang and J. Goodenough, ACS Energy Lett., 2016, 1, 633-637.

21 J. Liu, H. Yuan, X. B. Cheng, W. J. Chen, M. M. Titirici, J. Q. Huang, T. Q. Yuan and Q. Zhang, Mater. Today Nano, 2019, 8, 100049.

22 T. Zhang, B. Shen, H. Yao, T. Ma and S. Yu, Nano Lett., 2017, 17, 4894-4901.

23 T. Zhang, J. Chen, T. Tian, B. Shen, Y. Peng, Y. Song, B. Jiang, L. Lu, H. Yao and S. Yu, Adv. Funct. Mater., 2019, 29, 1902023.

24 X. Tan, W. Zhao and T. Mu, Green Chem., 2018, 20, 36253633.

25 F. Zhang, X. Lan, H. Peng and X. Hu, Adv. Funct. Mater., 2020, 30, 2002169.

26 Z. Wang, Y. Lee, S. Kim, J. Seo, S. Lee and L. Nyholm, Adv. Mater., 2020, 33, 2000892.

27 H. Tu, M. Zhu, B. Duan and L. Zhang, Adv. Mater., 2020, 33, 2000682.

28 Y. Wang, Z. Qiu, Z. Lang, Y. Xie, Z. Xiao, H. Wang, D. Liang, J. Li and K. Zhang, Adv. Mater., 2020, 33, 2005263.

29 Y. Xu, G. Zhao, L. Zhu, Q. Fei, Z. Zhang, Z. Chen, F. An, Y. Chen, Q. Cao and Z. Yan, Proc. Natl. Acad. Sci. U. S. A., 2020, 117, 18292-18301. 
30 T. Li, S. Li, W. Kong, C. Chen, E. Hitz, C. Jia, J. Dai, X. Zhang, R. Briber, Z. Siwy, M. Reed and L. Hu, Sci. Adv., 2019, 5, eaau4238.

31 F. Chen, A. Gong, M. Zhu, G. Chen, F. Jiang, Y. Li, Y. Wang, J. Dai, Y. Yao, J. Song, B. Liu, K. Fu, S. Das and L. Hu, ACS Nano, 2017, 11, 4275-4282.

32 T. Li, X. Zhang, S. D. Lacey, R. Mi, X. Zhao, F. Jiang, J. Song, Z. Liu, S. Das, R. Briber and L. Hu, Nat. Mater., 2019, 18, 608613.

33 T. Li, Y. Zhai, S. He, W. Gan, Z. Wen, M. Heidarinejad, D. Dalgo, R. Mi, X. Zhao, J. Song, J. Dai, C. Chen, J. Srebric, X. Yin and L. Hu, Science, 2019, 364, 760-763.

34 S. He, C. Chen, Y. Kuang, R. Mi, Y. Liu, Y. Pei, W. Kong, E. Hitz, X. Chen, A. Gong, J. Li, S. Das and L. Hu, Energy Environ. Sci., 2019, 12, 1558-1567.

35 S. Xu, C. Chen, Y. Kuang, J. Song, W. Gan, B. Liu and L. Hu, Energy Environ. Sci., 2018, 11, 3231-3237.

36 M. Wada, T. Okano and J. Sugiyama, J. Wood Sci., 2001, 47, 124-128.
37 M. Poletto, A. J. Zattera, M. M. Forte and R. M. Santana, Bioresour. Technol., 2012, 109, 148-153.

38 S. Wang, L. Zhang, A. Wang, X. Liu, J. Chen, Z. Wang, Q. Zeng, H. Zhou, X. J iang and L. Zhang, ACS Sustainable Chem. Eng., 2018, 6, 14460-14469.

39 J. Ye, Y. Cheng, L. Sun, M. Ding, C. Wu, D. Yuan, X. Zhao, X. Cheng and C. Jia, J. Membr. Sci., 2019, 572, 110-118.

40 K. Liu, Q. Jiang, S. Tadepalli, R. Raliya, P. Biswas, R. R. Naik and S. Singamaneni, ACS Appl. Mater. Interfaces, 2017, 9, 7675-7681.

41 G. Ding, B. Qin, Z. Liu, J. Zhang, B. Zhang, P. Hu, C. Zhang, G. Zhang, G. Xu, J. Yao and G. Cui, J. Electrochem. Soc., 2015, 162, A834-A838.

42 S. Gong, Y. Huang, H. Cao, Y. Lin, Y. Li, S. Tang, M. Wang and X. Li, J. Power Sources, 2016, 307, 624-633.

43 M. Zhu, J. Lan, C. Tan, G. Sui and X. Yang, J. Mater. Chem. A, 2016, 4, 12136-12143.

44 J. Kim, D. H. Kim, S. H. Joo, B. Choi, A. Cha, K. M. Kim, T. H. Kwon, S. K. Kwak, S. J. Kang and J. Jin, ACS Nano, 2017, 11, 6114-6121. 